\title{
Elevated DNA double strand breaks and apoptosis in the CNS of scid mutant mice
}

\author{
MC Vemuri ${ }^{1,2}$, E Schiller ${ }^{1}$ and JR Naegele ${ }^{\star, 1}$ \\ ${ }^{1}$ Program in Neuroscience and Behavior, Department of Biology, Wesleyan \\ University, Middletown, CT 06457, USA \\ 2 Permanent address: School of Life Sciences, University of Hyderabad, \\ Hyderabad, 500046, India \\ * Corresponding author: JR Naegele, Program in Neuroscience and Behavior, \\ Department of Biology, Wesleyan University, Middletown, CT 06457, USA. \\ Tel: (860) 685-3232; Fax: (860) 685-3279; E-mail: jnaegele@wesleyan.edu
}

Received 25.5.00; revised 6.10.00; accepted 31.10.00

Edited by CJ Thiele

\begin{abstract}
Genetic approaches have provided evidence that DNA endjoining problems serve an essential role in neuronal survival during development of mammalian embryos. In the present study, we tested whether the DNA repair enzyme, DNA dependent protein kinase, plays an important role in the survival of cerebral cortical neurons in mice. DNA-PK is comprised of a DNA-binding subunit called Ku and a catalytic subunit called DNA-PKcs. In mice with the scid mutation, DNAPKcs is truncated near the kinase domain, which causes loss of kinase activity. We compared the spatial and temporal aspects of neuronal cell death in scid versus isogenic wildtype embryos and found a significant increase in dying cells in scid mice, as assessed by nuclear changes, DNA fragmentation and caspase-3 activity. Additional biochemical and immunocytochemical studies indicated that of several DNA repair enzymes investigated, only PARP was increased in scid mice, possibly in response to elevated DNA strand breaks. Cell Death and Differentiation (2001) 8, 245-255.
\end{abstract}

Keywords: PCD; apoptosis; DNA repair; development; cortex; neuronal survival

Abbreviations: ATM, ataxia telangiectasia mutated; $\mathrm{CP}$, cortical plate; caspase, cysteine dependent aspartate-specific protease; DNA-PK, DNA dependent protein kinase, DNA-PKcs, DNA dependent protein kinase catalytic subunit; dsDNA, double stranded DNA; DTT, dithiothreitol; HR, homologous recombination; IZ, intermediate zone; NHEJ, non-homologous end joining; PARP, poly (ADP) ribose polymerase; PCD, programmed cell death; PMSF, phenylmethylsulfonyl fluoride; pNA, para-nitroaniline; RT, room temperature; scid, severe combined immunodeficiency; VZ, ventricular zone; WT, wild-type; XRCC4, X-ray repair cross complementation-4

\section{Introduction}

Growth of the central nervous system (CNS) requires strict control of both neuronal production and programmed cell death (PCD).${ }^{1-3}$ In the mammalian cerebral cortex, proliferation of neuronal progenitor cells occurs within the ventricular zone that surrounds the embryonic neural tube. These cells produce postmitotic neurons that migrate away from this zone, through the intermediate zone, to reach their final destinations within the cortical plate. Programmed cell death occurs within both the progenitor cell populations and among postmitotic cell populations in the embryonic and neonatal CNS. ${ }^{1}$ Although the signals that trigger cell death are poorly understood, recent work has established a link between neuronal PCD and two caspase family members. Caspase-9 appears to regulate death of proliferating cells in the neuroepithelium, whereas caspase- 3 has been found to regulate the death of postmitotic and differentiating neurons. $^{4-7}$ Elimination of either of these genes has lethal consequences, including extrusion of brain tissue outside of the skull due to brain overgrowth. ${ }^{7}$ Additional work has underscored the importance of a molecule involved in caspase activation called Apaf-1. Deletion of the gene encoding Apaf-1 also reduces PCD in the embryonic brain, resulting in excessive growth of the CNS. ${ }^{8,9}$

Although excessive neuronal survival results from a loss of caspase activation, recent work has suggested that massive numbers of embryonic neurons die without the activity of DNA repair enzymes. ${ }^{10,11}$ The association between DNA damage/repair and neuronal survival has not been well studied but the link may be a requirement for genetic recombination during the period of differentiation. ${ }^{2,3}$

Much of the current understanding of gene repair and recombination has come from studies of developing lymphocytes and radiation sensitive mammalian cell lines. Two types of double-stranded DNA repair that have been characterized are homologous recombination and nonhomologous end joining (NHEJ). Homologous recombination is the primary mechanism for DNA repair in yeast, but NHEJ prevails in mammalian cells. ${ }^{12}$ NHEJ makes use of a DNA-dependent protein kinase that consists of three subunits: the catalytic subunit called DNA-PKcs, and a heterodimer containing the proteins Ku70 and Ku80. ${ }^{13}$ Two additional proteins, DNA ligase IV and X-ray repair crosscomplementation-4 (XRCC4), interact to rejoin blunt ended DNA strands at break sites during DNA ligation reactions. ${ }^{12,14}$ DNA damage can also consist of single-strand base adducts. The DNA repair enzyme, PARP, may function during these repairs by transiently binding to sites of DNA damage. ${ }^{15}$ An additional DNA repair protein called ATM may sense DNA damage and send signals that halt the cell cycle during DNA repair processes. ${ }^{16,17}$

Studies utilizing gene-targeted deletion during mouse embryogenesis have helped to clarify which of these enzymes support neuronal survival during genesis of the nervous system. Recent knock-out studies of Ku70, Ku80, DNA ligase IV or XRCC4 showed that eliminating any of these genes causes massive PCD in the murine embryonic 
cerebral cortex. ${ }^{10,11,18}$ The most marked increase in PCD was observed in mice with complete disruption of DNA ligase IV or XRCC4. These embryos exhibited significant increases in pyknosis throughout the developing cerebral cortex, diencephalon, midbrain and spinal cord, and many died in utero. ${ }^{18,19}$ Less severe defects were found in Ku-deficient mice which had moderately elevated pyknosis, generalized growth defects, and dwarfism. ${ }^{11,20}$ By contrast, DNA-PKcs knockout mice were not found to have noticeable increases in pyknotic cells in the developing brain. However, as noted by the authors, a subtle defect in the DNA-PKcs deficient mice might have gone undetected. ${ }^{11}$ Both the Ku and DNA-PKcs deficient mice also develop immunodeficiency due to the critical role of DNA-PK protein complex in lymphocyte immunoglobulin gene rearrangements. ${ }^{10,11,21-24}$ The DNAPK protein complex has also been shown to mediate apoptotic signaling in neuronal cell lines. ${ }^{25}$ Additional studies have underscored the role of the DNA repair enzyme PARP in response to apoptotic stimuli; PARP knock-out mice exhibit greater sensitivity to a range of such stimuli, as well as abnormal growth and premature deaths. ${ }^{26,27}$

Surprisingly, analyses of PCD have not been done in the nervous system of scid mice, a mutant strain that expresses a truncated and enzymatically inactive form of DNA-PKcs protein. Since the mutated form of the DNAPKcs protein expressed by scid mice is still capable of binding to DNA through the $\mathrm{Ku}$ subunit, studies of these mice might reveal a role for DNA-PKcs that had been missed in studies employing gene knock-out strategies. For this reason, we examined PCD in the scid mouse CNS by the TUNEL method, in combination with assays for caspase-3 activity. In addition, since virtually nothing is known about whether DNA repair enzymes exhibit differential expression patterns during CNS development, we analyzed how the expression of these enzymes varied during the course of normal and scid CNS development using immunocytochemical and Western blotting approaches. Notably, we have found a marked increase in TUNEL positive neurons in scid mice as well increased caspase- 3 activation and PARP. Taken together, these findings implicate the DNA-PK catalytic subunit in neuronal survival and differentiation.

\section{Results}

Morphological changes in apoptotic cells are often indicative of PCD in the nervous system. ${ }^{28}$ These changes include nuclear condensation (pyknosis) and membrane blebbing, which are often visualized by light or fluorescent microscopy using chromatin stains or analyses of morphological changes at the electron microscopic level. ${ }^{29}$ DNA fragmentation and caspase- 3 are also often associated with neuronal PCD. In the present study, we combined three of these methods to visualize morphological and biochemical markers for PCD.

\section{Increased PCD in scid cortex}

Hoechst staining of E14.5 scid and wild-type (WT) cerebral cortex revealed normal patterns of cortical lamination in both WT and mutant mice (Figure $1 A, B$ ). These sections were also stained with the TUNEL method to identify fragmented DNA (Figure 1C,D). A striking increase in TUNEL ${ }^{+}$cells was evident in the cerebral hemispheres of scid versus WT mice (Figure $1 \mathrm{C}, \mathrm{D}$ ). In both strains, the $\mathrm{TUNEL}^{+}$cells had similar distributions and were located mainly in deeper layers of the cerebral cortex. However in scid mice, there were many more $\mathrm{TUNEL}^{+}$cells within the intermediate zone. The third marker was an antibody recognizing active caspase-3 (Figure 1E,F). Labeled cells were predominantly found in the intermediate zones and lower cortical plate. In scid embryos, there was a striking increase in the number of cells containing active caspase-3. The results of triple staining to visualize nuclei, TUNEL, and caspase-3 are shown across the bottom of Figure 1. TUNEL ${ }^{+}$cells (Figure $1 \mathrm{H}, \mathrm{K}$ ) typically had pyknotic nuclei (Figure $1 \mathrm{G}, \mathrm{J}$ ) and active caspase-3 (Figure $1 \mathrm{I}, \mathrm{L}$ ). These results indicate that many of the cells were dying by an active process involving nuclear condensation, DNA fragmentation and caspase-3 activation.

To quantify the association between DNA fragmentation and caspase- 3 activity, we quantified the percentage of $\mathrm{TUNEL}^{+}$and caspase $-3^{+}$cells in the cerebral hemispheres of scid and WT mice and the results are shown in Figure 2. On embryonic day 14.5 (E14.5), approximately $1.7 \%$ of scid cortical neurons were $\mathrm{TUNEL}^{+}$and $0.8 \%$ were caspase- $3^{+}$. By contrast, WT embryos had only $0.4 \%$ TUNEL $^{+}$cells and only $0.2 \%$ caspase $-3^{+}$cells. These differences were highly significant and suggest there is a fourfold increase in programmed cell death in scid embryos at this age. In newborn scid mice, a twofold increase in TUNEL ${ }^{+}$cells was found, although this difference was not statistically significant. No differences were found for caspase-3 staining between strains at this age. TUNEL and caspase-3 staining were also examined in P8 brains and no significant differences were found.

Although these findings suggested elevated programmed cell death in scid embryos, we also wished to determine whether the increase in caspase-3 immunoreactivity was associated with an increase in caspase-3 enzymatic activity. To address this question, we performed in vitro enzymatic assays for caspase- 3 in a more extensive series of embryos and postnatal mice. As shown in Table 1, there was a significant increase in caspase-3 activity in E14.5 scid cortex compared with WT cortex. However, differences in caspase-3 activity were not found at older ages, consistent with the findings presented above showing low levels of TUNEL ${ }^{+}$and caspase-3 staining after birth in both WT and scid mice.

\section{DNA repair enzymes are dynamically regulated}

To determine whether increased PCD in embryonic scid cortex correlated with differences in the spatio-temporal distribution of DNA-PKcs, ATM or PARP, immunohistochemical and Western blot analyses of embryonic WT and scid cortical extracts were performed and the results are shown in Figure 3. DNA-PKcs immunoreactivity was present in the cerebral cortex of WT mice on E14.5. The most intense staining for DNA-PKcs was found in the uppermost region of the cortical plate. These cells were identified as differentiated neurons by using the neuronal marker $\mathrm{Hu}$ (Figure $3 \mathrm{~J}-\mathrm{K}$ ). 


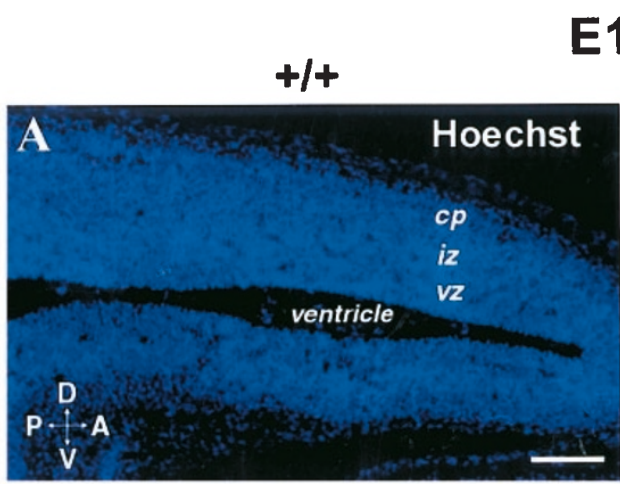

E14.5
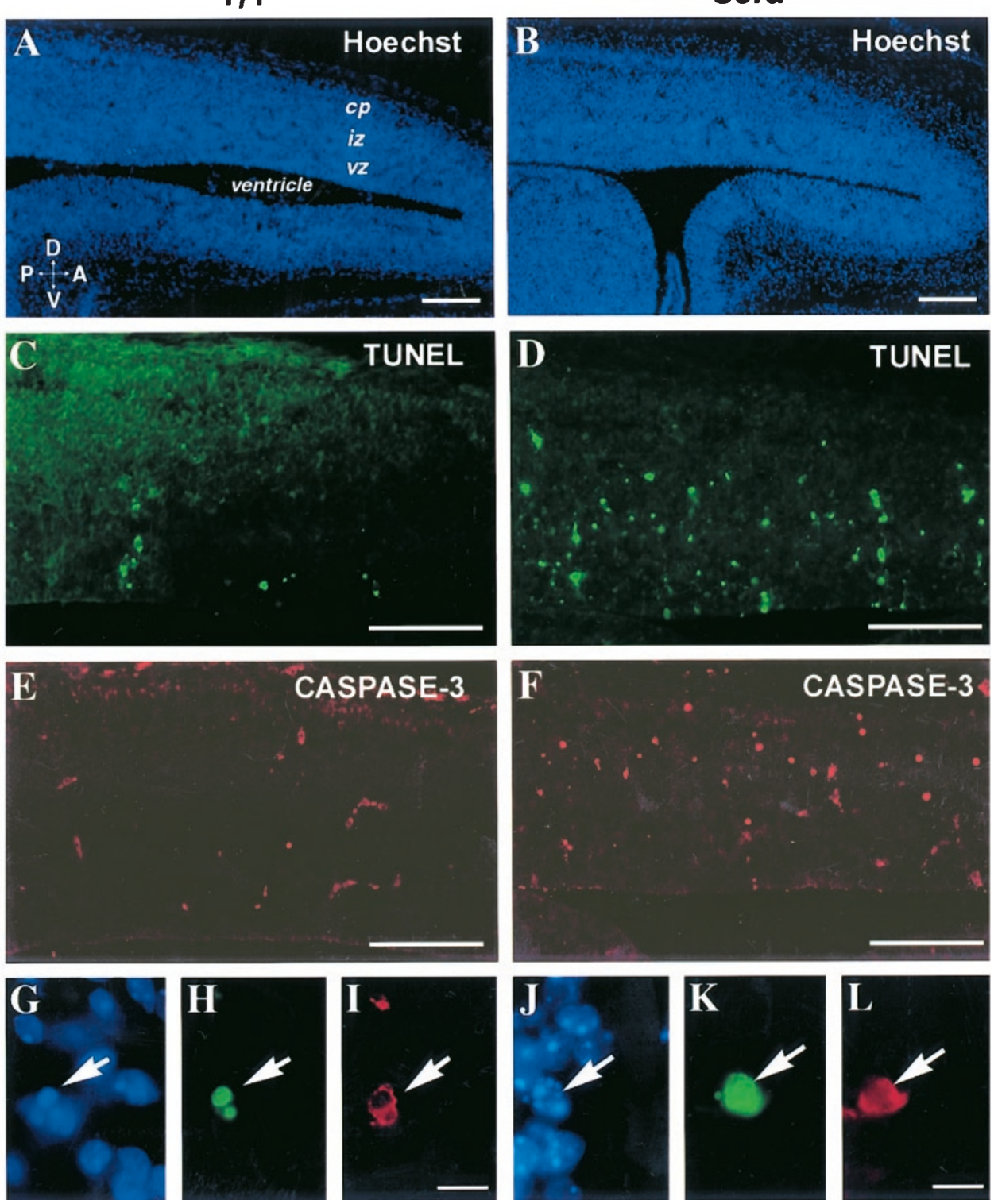

Figure 1 Patterns of programmed cell death in the cerebral cortex of newborn WT and homozygous scid mice. DNA fragmentation was assessed by fluorescent TUNEL staining and cells expressing active caspase-3 were localized with a caspase-3 specific antibody. Low power views of the cerebral cortex stained with Hoechst-33342 are shown in $+/+(\mathbf{A})$ and (B) cortex. (C) and (D) show TUNEL positive cells at a higher magnification, throughout the intermediate zone and cortical plate in $+/+(\mathbf{C})$ cortex. In contrast to the WT pattern of staining, a striking increase in TUNEL stained cells were noted in scid (D). (E) and (F) show caspase-3 positive cells. (G), (H) and (I) show triple labeled cells in $+/+$ mice and $(\mathbf{J}),(\mathbf{K})$ and $(\mathbf{L})$ are from scid mice. (G) and (J) Hoechst 33342 (blue) to show apoptotic nuclear morphology, (H) and (K) TUNEL (green) indicating DNA fragmentation. (I), (L) Active Caspase-3 immunoreactivity is shown in red fluorescence. Scale $=50 \mu \mathrm{m}$ in $\mathbf{A}, \mathbf{B}$. Scale $=100 \mu \mathrm{m}$ in $\mathbf{C}-\mathbf{F}$. Scale $=10 \mu \mathrm{m}$ in $\mathbf{G}-\mathbf{L}$

Weaker staining was noted extending into the intermediate zone, while the ventricular zone was largely unstained. Western blots of WT cortex showed the presence of three DNA-PKcs polypeptide bands with a mobility of 460,250 and $230 \mathrm{kDa}$ (Figure 3C). The 250-kDa band has been reported to be an inactive cleavage product of DNA-PKcs, generated by caspase-3 proteolysis during cell death. In contrast to the pattern observed in WT brain, the cleaved and inactive form of DNA-PKcs was the predominant band present in the scid cerebral cortex. These findings are consistent with previous reports suggesting that the scid defect is a point mutation in the $3^{\prime}$ terminus of DNA-PKcs that renders the translated protein unstable and reduces or abolishes the kinase activity of this enzyme.

The second DNA repair enzyme studied was ATM. Antibodies specific for this protein gave strong staining in most layers of the embryonic mouse cerebral cortex on E14.5 and no differences between WT and scid mice were 


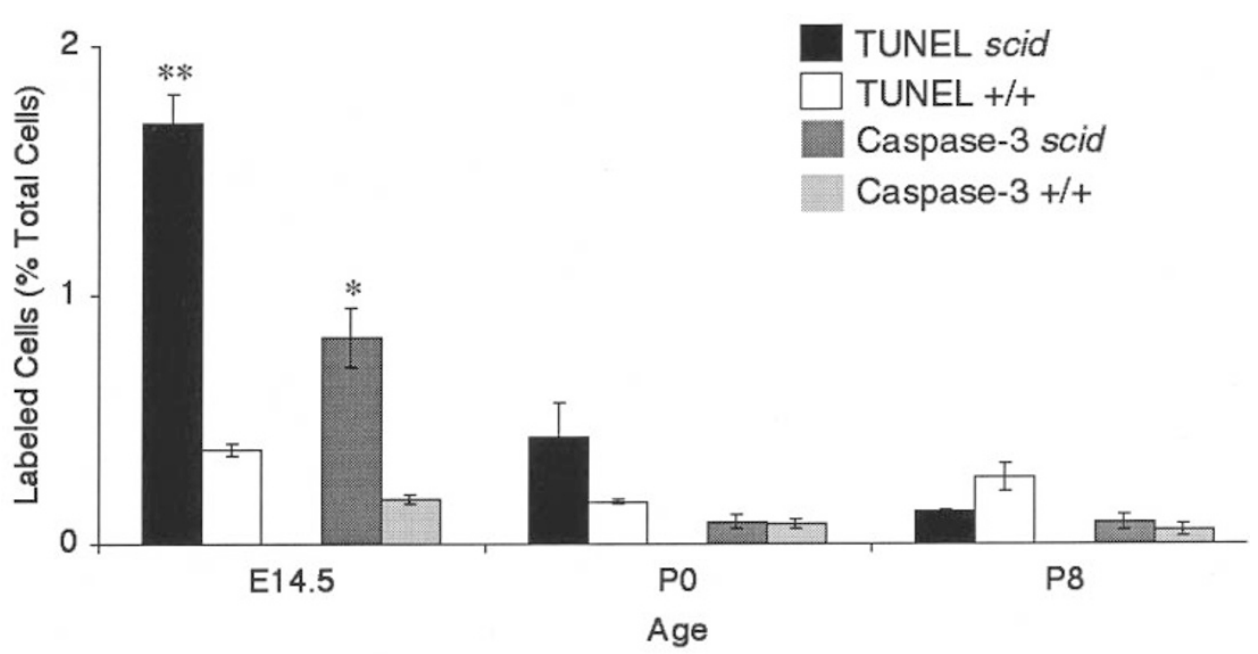

Figure 2 Analysis of apoptotic cells in the cerebral cortex of scid in WT mice on embryonic day E14.5 and postnatal days P0 and P8. The percentage of cells with DNA fragmentation is shown for scid (black bars) and WT (white bars) mice. The percentage of cells with caspase-3 immunoreactivity is shown for scid (dark gray bars) and WT (light gray bars) mice. Each bar represents a sample size of over 16000 total cells/age/strain. A minimum of four sections in 4-5 mice/strain/age was used to obtain the samples. Error bars represent \pm S.E.M. Significance values for a two-tailed $t$-test were $\geqslant 0.01\left({ }^{*}\right)$ and $\geqslant 0.0002\left({ }^{* *}\right)$

Table 1 Strain differences in levels of caspase-3 activity in the cerebral cortex

\begin{tabular}{lccc}
\hline & E14.5 & P0 & P8 \\
\hline WT & $702.34 \pm 137.80$ & $1154.7 \pm 288.66$ & $702.34 \pm 215.264$ \\
scid & $1976.09 \pm 109.10$ & $999.95 \pm 292.31$ & $880.90 \pm 303.73$ \\
Statistics & $P<0.0025$ & NS & NS \\
\hline
\end{tabular}

Caspase- 3 activity is expressed in $\mu$ moles of pNA formed $/ \mathrm{mg}$ protein $/ \mathrm{h}$

observed (Figure 3D,E). Western analyses shown in Figure $3 \mathrm{~F}$ indicate that the antibody we used labeled a single polypeptide band of approximately $370 \mathrm{kDa}$ in both WT and scid mice.

The third DNA repair protein examined was PARP. We observed distinct differences between WT and scid mice with this antibody. In WT mice, the telencephalon was weakly stained. In contrast, the ventricular zones and cortical plate of the scid telencephalon were strongly labeled (Figure 3G,H). Western blot analyses showed that this antibody reacted with two bands of 116 and $85 \mathrm{kDa}$, which match the predicted sizes of full-length PARP and the smaller, caspase-3 cleavage product (Figure $3 \mathrm{I}$ ).

To determine whether the expression patterns of DNAPKcs, ATM and PARP were developmentally regulated in WT and altered in scid CNS, we carried out immunostaining experiments in postnatal day 7 mice and the findings are shown in Figure 4. In P7 WT and scid mice, immunoreactivity for DNA-PKcs (Figure 4A,B) was present throughout layers 2-6 of the cerebral cortex (ctx). Outer layers gave more intense labeling while deeper layers closer to the white matter (wm) were weakly stained, suggesting an age-dependent decrease in staining. Intense staining was also noted in the hippocampus (hp). In addition to cellular labeling, WT cortex exhibited slightly higher background staining, which was most likely due to the presence of maternally derived immunoglobulin molecules in embryonic and postnatal brain tissue. ${ }^{30,31}$
To directly compare the levels of DNA-PKcs and to validate the specificity of the antibodies, age-matched samples were also probed by Western blotting and the results are shown in Figure $4 \mathrm{C}$. The DNA-PKcs immunoreactive polypeptide of $460 \mathrm{kDa}$ was detected in WT samples at this age as well as a lower molecular weight band of $250 \mathrm{kDa}$. In contrast to the pattern observed in WT samples, scid cortical extracts had much lower levels of the full-length form of DNA-PKcs, concurring with previous studies in scid lymphocytes ${ }^{32}$ and the lower molecular weight of $250 \mathrm{kDa}$ was the major band detected (Figure 4C). For comparison, when HeLa cell extracts were probed with the same antibody, the full-length $460-\mathrm{kDa}$ form of DNA-PKcs was strongly immunoreactive (Figure 4C, HeLa). Additional bands present in the HeLa extracts appear to be non-specific since they were not detected in murine samples which were immunoprecipitated before loading on the gels. The results in murine brain suggest that although full length DNA-PKcs is normally expressed, a cleaved form is more abundant and predominates in scid mice.

ATM immunoreactive staining was also intense in all cortical layers at this age (Figure 4D,E) and Western analyses showed comparable levels in WT and scid cortical extracts (Figure 4F). PARP staining was also compared at $\mathrm{P} 7$ and the immunoreactivity was considerably weaker in the WT cortex (Figure 4G) than scid cerebral cortex and hippocampus (Figure 4H). This difference appears to be specific for PARP, since staining for $\mathrm{Hu}$, a marker for differentiated neurons, was comparable between the two strains at this age (Figure 4G,H). Western blots staining for PARP also showed moderately increased levels of PARP in scid samples (Figure 4I). As a loading control for the PARP Western blots, the blot shown in Figure $4 \mathrm{I}$ was stripped and re-probed for glial fibrillary acidic protein (GFAP) and the results are shown in Figure 4L. No differences in GFAP were detected in these lanes, indicating equal loading of 

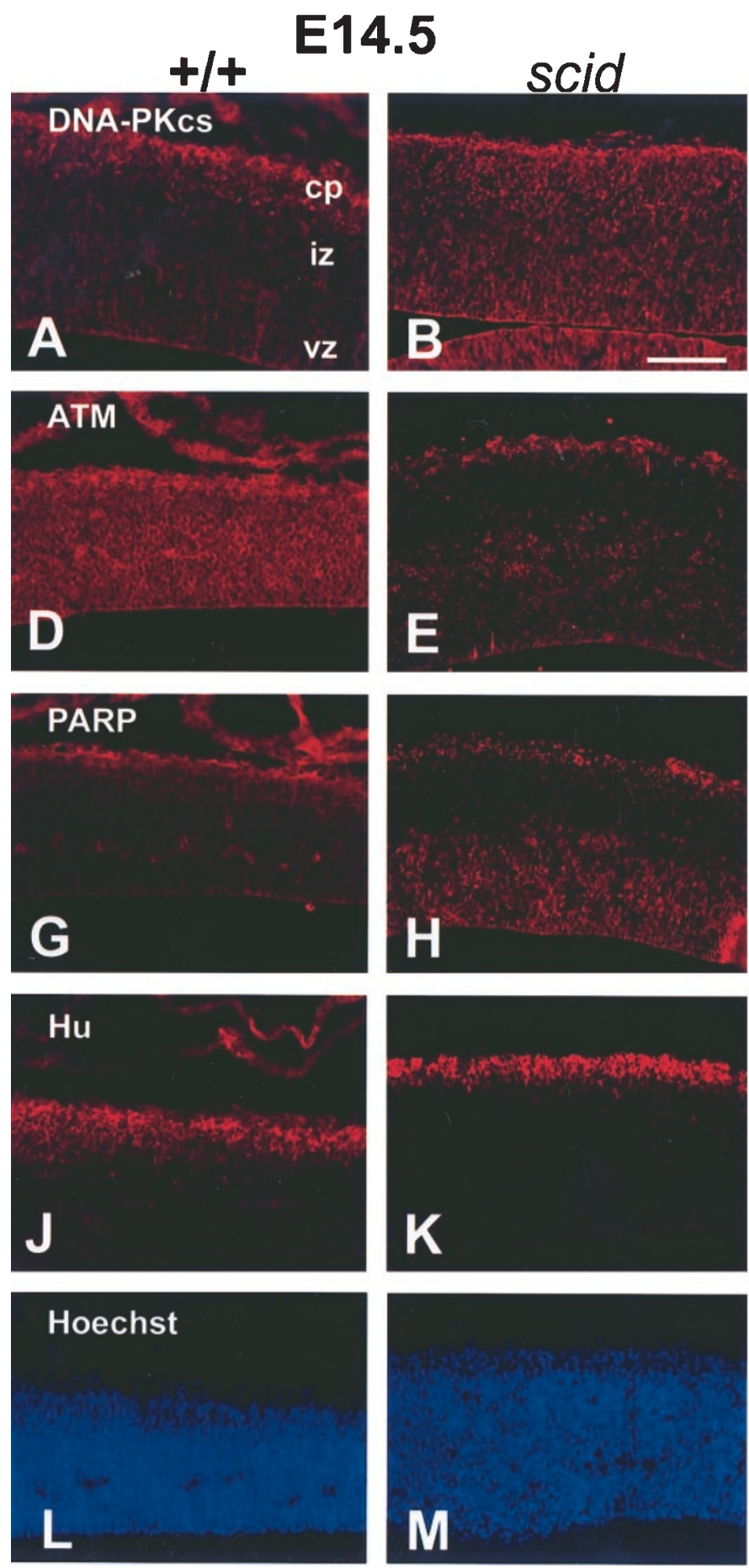
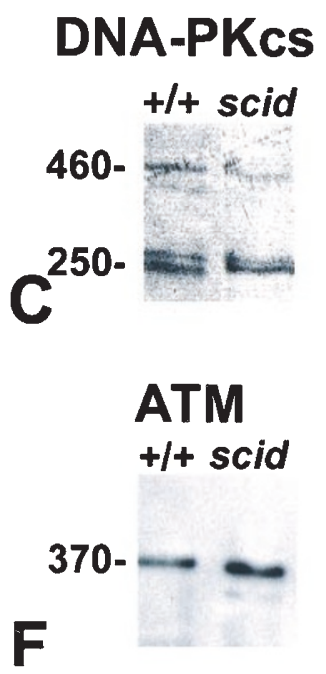

PARP

$+/+$ scid

116-

85-

Figure 3 DNA repair proteins visualized by immunostaining and Western blot analyses of the cerebral cortex of E14.5 wild-type (+/+) and scid mice. DNA-PKcs immunoreactivity in $+/+$ cortex $(\mathbf{A})$ versus scid cortex (B) is localized throughout the cortical plate (cp) and intermediate zones (iz). (C) Shows a Western blot analysis of embryonic mouse cerebral cortex. DNA-PKcs antibodies recognize a band of $460 \mathrm{kDa}$ corresponding to the full-length DNA-PKcs, as well as two cleavage products migrating at 250 and $230 \mathrm{kDa}$. Notably, levels of the full-length DNA-PKcs are severely reduced in scid cerebral cortex. ATM immunoreactive cells were distributed similarly in the cortical plate and intermediate zones of the cerebral cortex of $+/+$ (D) scid (E) mice. Western blot analyses show a single ATM reactive polypeptide of $370 \mathrm{kDa}$ in both $+/+$ and scid cortical extracts $(\mathbf{F})$. Immunofluorescence visualization of PARP in $+/+(\mathbf{G})$ and $s c i d(\mathbf{H})$ sections show staining in the ventricular zone and cortical plate of scid mice, but only weak immunoreactivity in the cortical plate of $+/+$ mice. Two PARP reactive bands were detected by immunoblot analyses with a mobility of 116 and $85-\mathrm{kDa}(\mathrm{I})$. The $116-\mathrm{kDa}$ band showed slight enrichment in scid tissues. Post-mitotic and differentiating neurons were detected with the early neuronal marker Hu in $+/+(\mathbf{J})$ and $s c i d(\mathbf{K})$ followed by a general nuclear counterstain (Hoechst) as shown in $+/+(\mathbf{L})$ and $s c i d(\mathbf{M})$. Scale bar $=100 \mu \mathrm{m}$ 


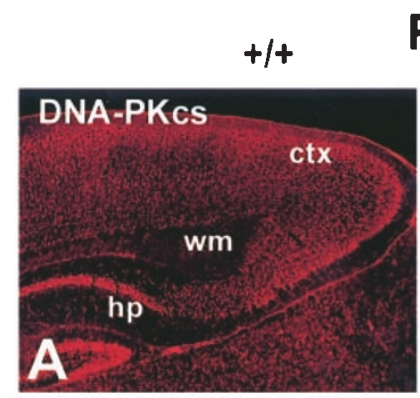

P7 scid
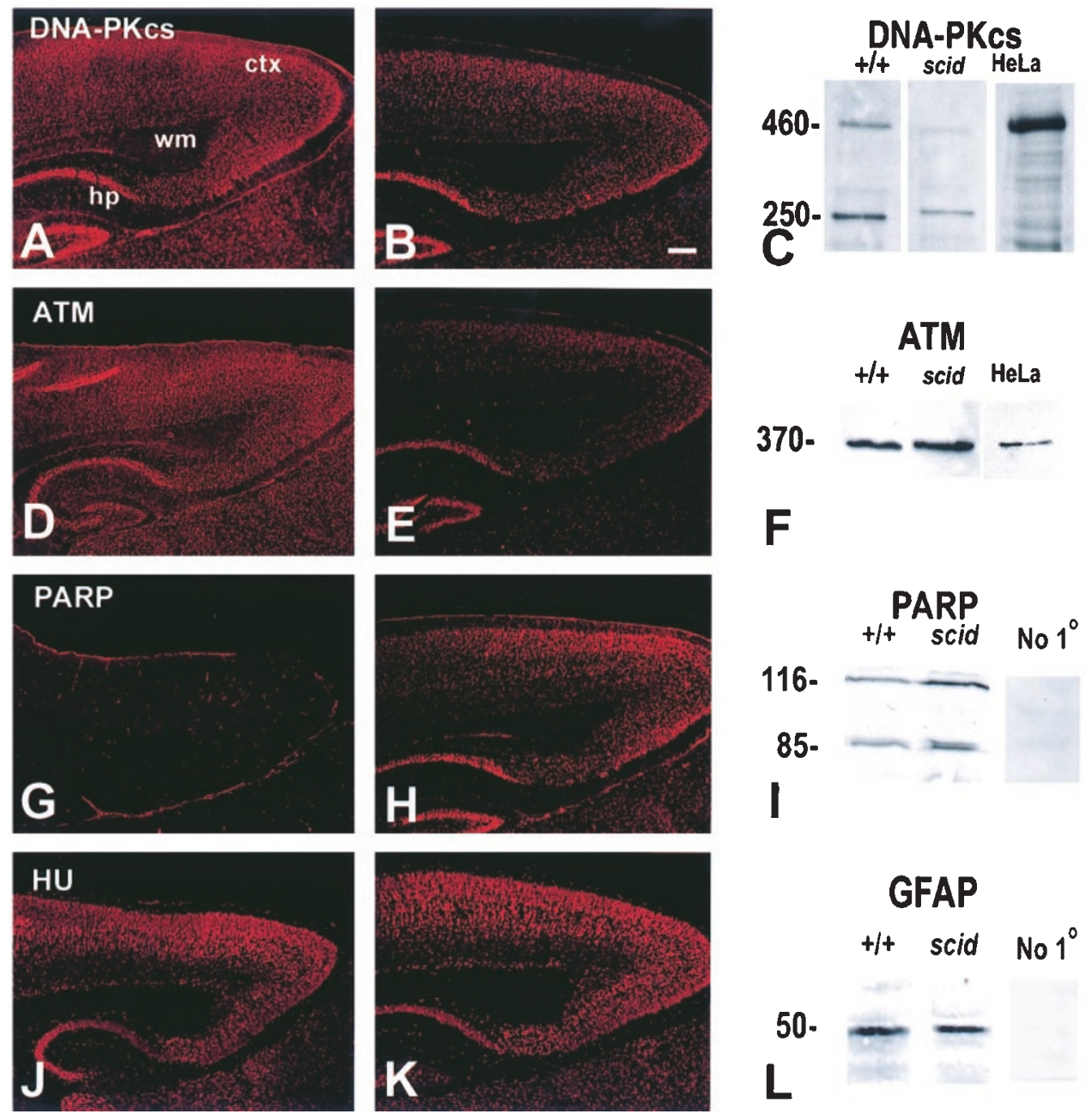

Figure 4 Immunofluorescence comparison WT and scid cortex showing the distribution of DNA repair proteins at 1 week of age. No strain differences were found in DNA-PKcs immunoreactivity is between WT $(+/+)(\mathbf{A})$ and scid $(\mathbf{B})$ cortex. DNA-PKcs was detected in nuclei throughout the cortex (CTX) and hippocampus (HC), but no labeling was observed in the white matter (WM). ATM immunoreactivity in $+/+$ (C) and scid (D) was similar to the DNA-PKcs staining at this age. PARP immunoreactivity was not detected in $+/+(E)$ cortex at this age, whereas higher levels were found in scid $(\mathbf{F})$. Comparable staining levels for the general neuronal marker, Hu were found in both strains $(\mathbf{G}, \mathbf{H})$. Scale bar=100 $\mu \mathrm{m}$. Immunoblot data for DNA-PKcs (C), ATM (F), PARP (I) and GFAP (L) are shown for P8 wild-type (+/ + ) and scid cortical extracts. Murine cortical samples were first immunoprecipitated for the immunoblots of DNA-PKcs as described in Materials and Methods and the blots were probed with the same antibody. HeLa cell extracts show abundant full-length DNA-PKcs (HeLa, C). (F) ATM levels were comparable in both WT (+/+) and scid cerebral cortex. Hela cell extracts were probed for ATM protein as a positive control. (I) Specificity of PARP staining was demonstrated by omitting the primary antibody (no $1^{\circ} ;+/+$ P60 cortical extract). (L) Equal protein loading for each age and strain was determined for the blot shown in (I ) by stripping and reprobing the blot for GFAP

the WT and scid samples. Further tests of the specificity of the DNA-PKcs and ATM reactive bands were performed using HeLa cell extracts (Figure 4C,F). As shown in Figure 4C, levels of full-length DNA-PKcs were considerably higher in HeLa cells than in the murine brain. An ATMreactive band of comparable size was also detected in HeLa extracts as well (Figure 4F). Omission of the primary antibodies was also carried out on sections (data not shown) and Western blots (Figure $4 \mathrm{I}, \mathrm{L}$ ) to verify that the primary antibody staining was specific. No staining was detected under these conditions. Taken together, the immunocytochemical and Western analyses presented here suggest that during normal CNS development, levels of PARP are low in comparison to DNA-PKcs and ATM. With maturation, PARP levels increase, and DNA-PKcs levels remain fairly constant.

\section{Reductions in the kinase activity of DNA-PKcs in scid CNS}

The DNA-PK pull down assay ${ }^{33}$ was optimized to detect DNAPK activity from the cerebral cortex extracts of WT and scid mice. DNA-PK activity was detected in cerebral cortices of both WT and scid mice at all ages examined (P0, 8, 30, 60). However, relative to the high activity in HeLa cells, we found one-tenth the level of DNA-PK activity in WT and approxi- 
mately one twentieth in scid cortex on P0. During postnatal maturation, we observed a fourfold increase in the level of DNA-PK activity in WT and scid cerebral cortex (Table 2).

\section{Discussion}

Transgenic mice lacking DNA repair enzymes such as DNA ligase IV, XRCC4, or Ku70/80 exhibit massive neuronal cell death during embryonic periods and increased embryonic lethality. In the present study, we investigated the role of a fourth DNA-repair enzyme, DNA-PKcs, during genesis of the mouse cerebral cortex. We also studied the spatio-temporal patterns of DNA-PKcs expression and compared this with two additional DNA repair enzymes: the ataxia telangiectasia mutated protein (ATM), and poly (ADP) ribose polymerase (PARP).

DNA-PK is a heterotrimeric protein, consisting of the DNA dependent protein kinase catalytic subunit (DNAPKcs) and a DNA binding complex of Ku80 and Ku70. Both $\mathrm{Ku}$ subunits can bind DNA, but the Ku80 subunit interacts specifically with DNA-PKcs. ${ }^{34}$ The scid defect introduces a point mutation in the terminus of the gene encoding DNA-PKcs, resulting in an abnormal stop codon. These mice express a truncated form of this protein ${ }^{32}$ with reduced kinase activity.

The central finding of this study is a significant increase in PCD in the brains of embryonic scid mice. This observation is supported by a number of lines of evidence. First, TUNEL staining for DNA fragmentation showed a fourfold increase in scid versus WT mice at embryonic ages and this correlated with the presence of pyknotic morphology. We also found in scid embryonic brains, that there was a significant increase in the number of cells staining for active caspase-3. Additional in vitro caspase- 3 activity assays confirmed and extended this finding by showing elevated activity in embryonic scid cortex relative to WT cortex. To further establish a link between DNA-PKcs and the elevation in dying cells, we measured differences in DNA-PK activity between WT and scid mice and showed a significant loss of activity in scid brain. Taken together, these observations suggest that in differentiating neurons, deficits in DNA repair and the presence of sustained DNA strand breaks elevate caspase-3 mediated programmed cell death.

\section{Does the survival and differentiation of immature neurons require DNA repair?}

Prior work has established that DNA end-joining proteins serve critical anti-apoptotic roles during periods of neurogen- esis. ${ }^{10,18}$ It has been speculated that these proteins participate in generating CNS cell type diversity and cellular receptors through gene rearrangements in differentiating neurons. ${ }^{2,35}$ Although we found evidence in scid mice that DNA-PKcs is involved in neuronal survival, a previous study using DNA-PKcs knock-out mice did not find CNS defects. ${ }^{11}$ This apparent discrepancy may be technical since the previous study relied on pyknotic morphology rather than other means of detecting cell death. Additionally, there may be strain differences. The scid mutation in C.B.-17 mice appears to cause a significant elevation in dying neurons during embryonic brain development and growth reductions postnatally, but neither was observed by the previous investigators in a different mouse strain. ${ }^{11}$ In contrast, eliminating the genes for $\mathrm{Ku}$, XRCC4, or DNA-ligase IV, caused striking reductions in brain size due to the massive numbers of dying cells. ${ }^{10,11}$ Current studies in our laboratory are attempting to address these issues by directly comparing levels of cell death in scid versus DNA-PKcs knockout mice to determine whether additional qualitative and/or quantitative differences exist.

Other differences between the current study and previous work may also account for our findings. The presence of a dysfunctional DNA-PK enzyme in the scid may be critical. It has been established that the scid mutation results in expression of a truncated form of DNAPKcs with significantly impaired kinase activity resulting in a growth disadvantage. $^{56}$ The mutant form of DNA-PKcs would still be likely to form a heterodimer with $\mathrm{Ku}$ and bind to DNA double strand breaks, since the domains responsible for DNA-PKcs: $\mathrm{Ku}$ heterodimerization and DNA binding are not affected by the scid mutation. The presence of the scid mutant DNA-PK protein could hinder DNA repair by preventing access of other, functionally redundant repair enzymes from the site of DNA damage. In essence then, the scid mutation might act as a dominant negative mutation. If so, it could result in a phenotype not detected in prior studies using gene deletion approaches. Along these lines, it would be of interest to test in WT neurons, whether expression of a dominant negative form of DNA-PKcs blocks DNA repair. Further studies of neuronal differentiation in the scid CNS may provide insights into the role of DNA end-joining proteins in neuronal survival.

\section{Cleavage of DNA-PK in the mouse CNS during periods of programmed cell death}

Earlier work showed that DNA-PKcs is cleaved following induction of apoptosis into three fragments of $\sim 230-250$,

Table 2 DNA-PK activity levels

\begin{tabular}{lcccc}
\hline Tissue source & P0 & P8 & P30 & P60 \\
\hline$+/+$ Cortex & $113.23 \pm 7.22$ & $166.48 \pm 35.58$ & $329.81 \pm 50.31$ & $443.83 \pm 46.23$ \\
scid cortex & $46.24 \pm 8.02$ & $61.18 \pm 20.89$ & $115.49 \pm 25.11$ & $235.54 \pm 43.53$ \\
Statistics & $P<0.0007$ & $P<0.0001$ & $P<0.0001$ & $P<0.0003$ \\
HeLa cells & $1165.11 \pm 123.21$ & & & \\
\hline
\end{tabular}

DNA-PK activity is expressed as picomoles of ATP incorporated $/ \mathrm{min} / \mu \mathrm{g}$ of protein 
$150-165$ and $120 \mathrm{kDa}^{37-39}$ The preponderance of these different forms depends on the intensity and duration of apoptotic stimuli. Loss of function occurs when DNA-PKcs is cleaved, which can result in DNA repair defects. ${ }^{37-39}$ Despite the large body of previous work on DNA-PKcs, very little is known about the function and biochemical properties of this molecule in postmitotic neurons or its role in programmed cell death. To detect DNA-PKcs in either WT or scid brain extracts; we employed a highly sensitive method that included immune precipitation of DNA-PKcs from whole cell extracts of cerebral cortex and Western blot detection by ECL using a cocktail of antibodies recognizing different portions of the molecule. In WT mouse embryonic and postnatal mouse cerebral cortex extracts, we detected the full-length form of DNA-PKcs, as well as proteolytic fragments with mobilities of 250 and $230 \mathrm{kDa}$. Comparisons between E14.5 and P8 WT brain extracts showed that the $460-\mathrm{kDa}$ band was the major DNA-PKcs reactive band detected at both ages. By contrast, this band was barely detected at any age in extracts scid brain, where the prevalent forms appear to be the cleavage products. Overall, our results are in general agreement with previous studies in which DNA-PKcs levels were found to be extremely low in most murine tissues. ${ }^{40}$ In previous studies, the truncated form of DNA-PKcs was also detected in scid mouse lymphocytes. ${ }^{32,41}$ Despite the presence of extensive protease inhibitors during biochemical extractions, our cortical extracts contained primarily the cleaved forms of DNA-PKcs in both the WT and scid mice. These results suggest that in vivo cleavage by endogenous proteases, such as caspases may generate the products we detected in both WT and scid brains. It is not yet clear why the truncated form of DNA-PKcs resulting from the scid mutation is more susceptible to cleavage. Possible explanations include increased caspase activity or lack of stability for other reasons.

Our immunostaining and Western blot assays suggested that levels of DNA-PKcs protein were relatively constant from embryonic to postnatal ages, but the kinase activity assays indicated increased activation of DNA-PKcs postnatally. This apparent discrepancy may be due to developmentally regulated expression of the DNA binding protein $\mathrm{Ku}$ which has been shown to help target DNA-PKcs to DNA and thereby stimulate DNA-PKcs kinase activity. ${ }^{42}$ Alternatively, a number of other factors and protein-protein interactions have been found to regulate DNA-PK activity, ${ }^{13}$ including ADP-ribosylation by means of the DNA repair enzyme PARP ${ }^{43}$ as discussed below.

\section{Differential expression patterns of DNA repair enzymes during embryonic DNS development}

In addition to our immunocytochemical and biochemical studies of DNA-PKcs, we also examined the ATM gene product, a $370-\mathrm{kDa}$ protein that localizes within nuclei and cytoplasmic vesicles. ${ }^{44,45}$ ATM regulates cell cycle signaling pathways by stopping cell cycle progression after DNA damage has occurred, ${ }^{17}$ allowing DNA repair or initiation of PCD. Similar to DNA-PKcs, cleavage and inactivation of ATM by caspase- 3 during apoptosis is well-established. ${ }^{16}$ ATM is a member of the PI3-kinase family and shares considerable homology with DNA-PK. Functionally it also specifically senses DNA damage and participates in DNA repair. ${ }^{45,46}$ Deletion studies however, suggest that while this DNA damage-signaling enzyme is not involved in regulating early-occurring PCD during neurogenesis, it is necessary for maturation of the cerebellum. ATM deficient mice exhibit abnormal Purkinje cell development in the cerebellum and postnatal neurodegeneration. ${ }^{47}$ More significantly, mutations of the ATM gene in humans cause a severe neurodegenerative disorder called ataxia telangiectasia. ${ }^{48}$ In both WT and scid cerebral cortices, ATM was expressed in a pattern similar to DNA-PKcs. However, ATM protein levels were moderately high in mouse brain and did not require immunoprecipitation for detection on Western blots. ATM protein levels were relatively constant from birth to $\mathrm{P} 30$ but decreased slightly in 2-month-olds. The basis for the decline in the levels of ATM and in the brain appears to be down-regulation of the gene. ${ }^{45}$

PARP is the third repair enzyme we compared in WT and scid mouse cerebral cortex. Like DNA-PK and ATM, it has also been implicated in DNA repair and apoptosis. PARP also contains a caspase-3 cleavage site in its $N$ terminal DNA binding domain and inactivation by caspase-3 cleavage is associated with DNA fragmentation. ${ }^{39,49,50}$ During normal DNA repair, PARP binds at the site of damage and uses $\mathrm{NAD}^{+}$as a substrate to form a poly ADP ribose polymer chain until a critical length is reached. At this stage, PARP separates from the site of DNA damage and other enzymes appropriate the site to complete repairs. ${ }^{51}$

During periods of programmed cell death in the embryonic brain, we observed a strong correlation between high levels of TUNEL staining, caspase-3 activity, and cleavage of DNA-PKcs and PARP. These results are in agreement with studies of neuronal cell death showing that DNA-PKcs and PARP are high affinity substrates for caspase-3 cleavage. ${ }^{39,50,52}$ Although PARP protein was expressed at low levels in WT mice, we observed an elevation in the scid mouse brain that was detected by both Western blot and immunocytochemical staining. These findings suggest that levels of PARP may be increased in scid cells, possibly in response to DNA double strand breaks or as a feedback mechanism triggered by low activity of DNA-PKcs in scid cells. In support of this interpretation, previous in vitro studies have indicated that the catalytic subunit of DNA-PKcs is ADPribosylated by $\mathrm{PARP}$, which can stimulate the protein kinase activity of DNA-PKcs for its substrate proteins. ${ }^{43}$

Our findings of elevated TUNEL staining in the ventricular and intermediate zone of embryonic scid mouse cortex suggests a novel link between DNA-PK and neuronal survival or differentiation. Although we believe that the increase in DNA double strand breaks and the additional activation of caspase- 3 and PARP in scid neurons results in elevated cell death, scid mice do not show a striking decrease in brain size or abnormal cytoarchitecture. However, there may be defects that have gone undetected by routine histological methods and studies are currently underway to address this issue. An alternative interpretation is that the increased TUNEL staining reflects DNA damage that is non-lethal. However, the increased caspase- 3 activity in scid brains suggests 
that this is not the case. A third possibility is that there is some sort of increased genetic rearrangement in scid neurons. In support of this interpretation, studies of embryonic mouse brain carried out with the more sensitive ISEL+method have detected DNA double-strand breaks in a majority of embryonic neurons. ${ }^{53}$ It has been proposed that DNA double strand breaks and genetic rearrangements may be an important aspect of neuronal differentiation. ${ }^{2}$ The nature of these DNA double-strand breaks and their role in differentiation is not well understood and the possible significance has been debated elsewhere. ${ }^{2,3,54}$

In conclusion, we have demonstrated reduced levels of DNA-PKcs protein and loss of DNA-PK holoenzyme activity in the embryonic and postnatal scid mouse brain. During embryonic periods, these changes correlated with elevated caspase-3 activity, increased $\mathrm{TUNEL}^{+}$staining, and elevated levels of PARP. Our findings suggest that defective DNA-PK during periods of neuronal differentiation may reduce the viability of immature neurons and augment levels of programmed cell death.

\section{Materials and Methods}

All materials were obtained from Sigma (St. Louis, MO, USA) unless stated otherwise.

\section{Animals \\ Male and female Fox Chase C.B-17/lcrCr1-scid mice ${ }^{24}$ (homozygous scid, Taconic Laboratories) or isogenic normal male and female C.B.17 wild type mice $\left(^{+} /^{+}\right.$, Taconic laboratories) were mated in the Wesleyan Animal Facility and the offspring were maintained in a pathogen-free environment.}

\section{In situ DNA fragmentation}

To compare the percentage of apoptotic cells in scid versus wild-type mice, brains from embryos and postnatal pups were analyzed for DNA fragmentation with a fluorescent staining method. E14.5 embryos were fixed in $4 \%$ paraformaldehyde in $0.1 \mathrm{M}$ sodium phosphate buffer (Ph 7.4) by immersion, while P0 and P8 were collected by transcardial perfusion using the same fixative. All tissues were cryoprotected sequentially in 10, 20 and $30 \%$ sucrose solutions in $0.1 \mathrm{M}$ phosphate buffered saline. Twelve to $14 \mu \mathrm{m}$ thick brain sections were cut at the parasaggital plane and processed for DNA fragmentation using the manufacturer's protocol (Apoptag fluorescein kit, Intergen). Sections were then counterstained with Hoechst 33342 (1:5000, Molecular Probes). The apoptotic index at embryonic and postnatal ages was determined for mice ages E14.5 $(n=5), \mathrm{PO}(n=4)$, and P8 $(n=4)$. For each animal, a series of $4-5$ cryostat sections were stained and the number of stained cells per 1000 cells/section was determined.

\section{Detection and quantification of active caspase-3}

To compare the percentage of cells with fragmented DNA to another marker for programmed cell death, we detected cells containing active caspase-3 by immunofluorescence. Sections were incubated overnight in antibody S-398 (Smith-Kline Beacham; 1:2500; courtesy of Dr. Kristy Kikly) at RT. This antibody recognizes the cleaved and active form of caspase- $3 .{ }^{55,56}$ The bound antibody was localized with goat anti-rabbit IgG conjugated to Alexa 546 (1:400, Molecular
Probes). Sections were counterstained with Hoechst 33342 (1:5000, Molecular Probes) and mounted in Prolong Antifade solution (Molecular Probes). We assessed pyknotic morphology (Hoechst stain) and active caspase-3 staining by fluorescent microscopy and quantified the results by counting approximately 4000 cells from a series of 4-5 non-adjacent sections in $4-5$ animals from each strain.

\section{Detection of caspase-3 proteolytic activity}

Caspase-3 activity assay was carried out using the CaspACE Assay Kit (Promega). Briefly, the protein samples of murine cerebral cortex from different ages were used to cleave the substrate (Ac-DEVD-pNA). This substrate was pre-labeled with the chromophore $p$-nitroaniline (pNA). Free pNA released due to caspase-3 cleavage during the assay was measured using a spectrophotometer. Caspase-3 activity was calculated using pNA as standard and data were represented as $\mu \mathrm{mol}$ of pNA formed $/ \mathrm{hr} / \mathrm{mg}$ protein. Statistical analyses of the results were performed with Student's $t$-test.

\section{Preparation of protein extracts}

Cerebral cortices were dissected from embryonic $(E)$ or postnatal $(P)$ mice following $\mathrm{CO}_{2}$ overdose and cervical dislocation. Cerebral cortex was dissected from the brains of mice ages E14.5, P0, P8, P30, and P60 and placed in ice cold low salt buffer (1:3 WT/vol) consisting of $100 \mathrm{mM}$ HEPES pH 7.4, $100 \mathrm{mM} \mathrm{NaCl}, 25 \mathrm{mM} \mathrm{KCl}, 11 \mathrm{mM} \mathrm{MgCl}_{2}$, $1 \mathrm{mM}$ EDTA, $0.1 \mathrm{mM}$ DTT, $0.1 \mathrm{mM}$ PMSF and protease inhibitor cocktail (Sigma) containing 4-(2-aminoethyl)-benzenesulfonyl fluoride, pepstatin A, transepoxysuccinyl-L-leucylamido (4-guanidino) butane, bestatin, leupeptin and aprotinin used at a concentration of $50 \mu \mathrm{l} / \mathrm{gram}$ of tissue. The tissue was homogenized, then subjected to three freeze thaw cycles. This whole cell extract (WCE) was immediately processed for either activity assays or immunoblots. Protein concentrations were determined using the Coomassie dye protein staining kit (Pierce, Rockford, IL, USA).

\section{DNA-PK 'pull-down' kinase assay}

Due to low levels of DNA-PK activity in mice and other rodents, we used a sensitive 'pull-down' method. ${ }^{39}$ Double-stranded DNA (ds DNA) cellulose was first washed by incubating in $Z$ buffer $(25 \mathrm{mM}$ HEPES (pH 7.9), $50 \mathrm{mM} \mathrm{KCl}, 10 \mathrm{mM} \mathrm{MgCl}_{2}, 1 \mathrm{mM} \mathrm{DTT}, 5 \%$ glycerol, $0.5 \mathrm{mM}$ EDTA and $0.25 \mathrm{mM}$ EGTA) followed by two washes in high salt $Z$ buffer ( $Z$ buffer with $0.4 \mathrm{M} \mathrm{KCl}$ instead of $50 \mathrm{mM} \mathrm{KCl}$ ) and then re-equilibrated by three washes with $Z$ buffer prior to use. Aliquots of $100 \mu \mathrm{l}$ of WCE were incubated with $11 \mu \mathrm{l}$ of high salt extraction buffer ( $5 \mathrm{M} \mathrm{NaCl}, 100 \mathrm{mM} \mathrm{MgCl}_{2}$, and $10 \mathrm{mM} \mathrm{DTT}$ ), placed on ice for $5 \mathrm{~min}$, then microcentrifuged at $10000 \times g$ for $3 \mathrm{~min}$ at $4^{\circ} \mathrm{C}$. The supernatant was recovered carefully, diluted to $50 \mathrm{mM}$ salt concentration by the addition of 11 volumes of $50 \mathrm{mM}$ HEPES buffer $(\mathrm{pH} 7.5)$ and incubated with $30 \mu \mathrm{l}$ of dsDNA-cellulose at $4^{\circ} \mathrm{C}$ for $15 \mathrm{~min}$ on a rotator with gentle rocking. The protein-DNA complexes were washed in $Z$ buffer twice and used in the DNA-PK activity assay.

The slurry of DNA-PKcs bound to ds DNA-cellulose was resuspended on ice in $30 \mu$ l kinase buffer (25 mM HEPES ( $\mathrm{pH} 7.9$ ), $50 \mathrm{mM} \mathrm{KCl}, 10 \mathrm{mM} \mathrm{MgCl}_{2}, 1 \mathrm{mM}$ DTT, $5 \%$ glycerol, $0.5 \mathrm{mM}$ EDTA, $0.25 \mathrm{mM}$ EGTA and protease inhibitor mix) and used as enzyme source. After addition of $0.25 \mathrm{mM}\left(\gamma^{32} \mathrm{P}\right)$ ATP (NEN laboratories, Amersham $3000 \mathrm{Ci} /$ mmole; $1 \mu \mathrm{Ci}$ per reaction), the reaction was initiated. Either 4 nmoles of p53-derived peptide (EPPLSQEAFADLWKK) which is a proven substrate for DNA-PKcs or a mutant peptide (EPPLSEQAFADLWKK) that lacks the consensus phosphor- 
ylation site were added. The mutated peptide served as a negative control to detect non-specific phosphorylation by other kinases. After $10 \mathrm{~min}$ at $30^{\circ} \mathrm{C}$, the kinase assay was stopped by the addition of an equal volume of stop solution (30\% acetic acid, $10 \mathrm{mM} \mathrm{ATP,} \mathrm{and}$ $50 \mathrm{mM}$ EDTA, pH 8.0). The contents were spotted on Whatman P-81 phosphocellulose paper, washed three times with $15 \%$ acetic acid and the bound radioactivity was measured using a scintillation counter. Blank values were derived from a mock kinase reaction containing only dsDNA-cellulose without the protein sample. Statistical analyses of DNA-PK activity at each age and for each strain were performed using Student's $t$-test.

\section{Immunoprecipitation and immunoblot analysis}

Western analyses of DNA-PKcs were conducted with a mixture of three monoclonal antibodies (Ab-1, Ab-2 and Ab-3) purchased as a cocktail (Ab-4; 1:500 LabVision/NeoMarkers, Union City, CA, USA). The three monoclonal antibodies in this cocktail recognize epitopes on three separate regions of the DNA-PK catalytic subunit. While precise epitope mapping has not been done, information is available about the region of DNA-PKcs recognized by each (NeoMarkers). Ab-1 is specific for the amino terminus of DNA-PKcs between amino acids 1 2713. Ab-2 is specific for an epitope between amino acids 3998 and 4127 which includes the PI-3 kinase domain in the carboxyl terminus. $\mathrm{Ab}-3$, referred to as 'Ab42-27' in published work, is specific for a short fragment between amino acids 2713 and 3198 and recognizes cleaved DNA-PKcs in apoptotic cells. ${ }^{57}$

Due to the low abundance in murine CNS, DNA-PKcs was immunoprecipitated with $A b-4$ prior to Western blot analyses. Five hundred micrograms of WCE was incubated with Ab-4 overnight at $4{ }^{\circ} \mathrm{C}$ with gentle agitation, followed by absorption of bound DNA-PKcs onto Protein G-agarose. Beads were washed three times in lysis buffer (50 mM HEPES pH 7.4, $50 \mathrm{mM} \mathrm{NaCl}, 12.5 \mathrm{mM} \mathrm{KCl}, 5 \mathrm{mM} \mathrm{MgCl}$, $0.5 \mathrm{mM}$ EDTA, $0.1 \mathrm{mM}$ DTT, $0.1 \mathrm{mM}$ PMSF protease inhibitor cocktail (Sigma), 1\% Triton X-100) and resuspended in $20 \mu \mathrm{l} 2 \times$ sample buffer. ATM and PARP proteins were not immunoprecipitated prior to loading on gels. Samples were boiled for $5 \mathrm{~min}$ and resolved by SDS-PAGE. DNA-PKcs and ATM gels consisted of $6 \%$ SDS-polyacrylamide with an acrylamide bisacrylamide cross-linking ratio of $100: 1$. For analysis of PARP, samples were separated on $15 \%$ SDS-polyacrylamide gels with acrylamide/bisacrylamide cross-linking ratio of $28: 1$.

Proteins from SDS-PAGE gels were transferred by electrophoresis (Hoeffer Scientific Instruments) to polyvinylpyrrolidene difluoride (PVDF) membranes for $5 \mathrm{~h}$ at $200 \mathrm{~mA}$. Immunoblots were incubated in $5 \%$ dry milk in $50 \mathrm{mM}$ tris-buffer saline containing $0.1 \%$ Tween 20 (TBST) and then transferred to primary antibodies. Primary antibodies included mouse anti-DNA-PKcs (mouse anti-DNA-PK; NeoMarkers, 1:500), anti-ATM (mouse monoclonal $2 \mathrm{Ci}$; Genetex; 1:800), antiPARP (BioMol, 1:500), or anti-GFAP (rabbit anti-GFAP, Sigma, $1: 500)$. Blots were incubated overnight at RT. Subsequently, the blots were rinsed four times with TBST, incubated with biotinylated goat anti-rabbit IgG (for rabbit primary antibodies) or biotinylated horse antimouse lgG (for blots labeled with mouse primary antibodies) for $1 \mathrm{~h}$ at RT. After rinsing, blots were incubated in avidin-biotin-peroxidase complex (Vector Laboratories) for $1 \mathrm{~h}$ in TBST. Blots were then visualized by chemiluminescence (Chemiluminescence kit, New England Nuclear) using X-ray film (Kodak).

\section{Immunohistochemistry}

Mice were killed with $50 \mathrm{mg} / \mathrm{kg}$ sodium pentobarbital (Abbot Laboratories) and perfused via the aorta with $4 \%$ paraformaldehyde in $0.1 \mathrm{M}$ sodium phosphate buffer, $\mathrm{pH} 7.4$ for $15 \mathrm{~min}$ at RT. The brains were removed, postfixed in $4 \%$ paraformaldehyde and cyroprotected in 10,20 and $30 \%$ sucrose in $0.1 \mathrm{M}$ sodium phosphate buffer ( $\mathrm{pH} 7.4)$. Ten-micron thick cryostat sections were mounted onto Superfrost Plus slides (VWR) dried on a warm plate at $37^{\circ} \mathrm{C}$ and stored at $-70^{\circ} \mathrm{C}$ until use. For immunohistochemistry, slides were warmed to RT, sections were rehydrated in PBS, treated for nonspecific staining by incubating in blocking buffer $(0.1 \mathrm{M}$ phosphate buffer $\mathrm{pH} 7.4,10 \%$ fetal bovine serum and $0.1 \%$ Triton $\mathrm{X}-100$ ) prior to using primary antibodies. Primary antibodies included anti-DNA-PKcs (Serotec; 1:500) antiATM (rabbit polyclonal, Novus Biologicals; $1: 1000$ or mouse monoclonal $2 \mathrm{Ci}$, Genetex; 1:500), and anti-PARP (Bio Mol; 1:500 dilution). Neuronal marker Hu antibody (Oregon State University) was used at a 1:200 dilution. All incubations in primary antibodies were carried out overnight at RT followed by incubation in anti-mouse IgG or anti-rabbit IgG for $1 \mathrm{~h}$. For fluorescence microscopy, sections were processed after the primary antibodies into biotin-Extravidin conjugated to Cy-3 (Sigma Chemicals, 1:100). An additional DNA counterstain was performed in these sections using Hoechst 33342 (1:1000 Molecular Probes) and sections were mounted in ProLong Antifade (Molecular Probes).

\section{Acknowledgements}

The authors thank members of the Naegele lab including: Magda Chechlacz, Karen Gilliams-Francis, Joshua Gooley, Andrew Scott, Matt Daugherty, and Jenn Weiss for scientific discussions. In addition, we would like to thank Aruna Vemuri for technical assistance, Lisa Gagnon for animal husbandry and Paul Lombroso for helpful comments on the manuscript. This work has been supported by NSF grant IBN-9600974.

\section{References}

1. PettmannB and Henderson CE (1998) Neuronal cell death. Neuron 20:633-647

2. Chun J and Schatz DG (1999) Rearranging views on neurogenesis: neuronal death in the absence of DNA end-joining proteins. Neuron 22: 7-10

3. Gilmore EC, Nowakowski RS, Caviness Jr VS and Herrup K (2000) Cell birth, cell death, cell diversity and DNA breaks: how do they all fit together? Trends Neurosci. 23: 100-105

4. Kuida K, Zheng TS, Na S, Kuan C, Yang D, Karasuyama H, Rakic P and Flavell RA (1996) Decreased apoptosis in the brain and premature lethality in CPP32deficient mice. Nature 384: 368-372

5. Kuida K, Haydar TF, Kuan CY, GuY, Taya C, Karasuyama H, Su MS, Rakic P and Flavell RA (1998) Reduced apoptosis and cytochrome c-mediated caspase activation in mice lacking caspase 9. Cell 94: 325-337

6. Hakem R, Hakem A, Duncan GS, Henderson JT, Wood M, Soengas MS, Elia A, De La Pompa JL, Kagi D, Khoo W, Potter J, Yoshida R, Kaufman SA, Lowe SW, Penninger JM and Mak TW (1998) Differential requirement for caspase 9 in apoptotic pathways in vivo. Cell 94: 339-352

7. Zheng TS and Flavell RA (1999) Apoptosis. All's well that ends dead [news]. Nature 400: 410-411

8. Yoshida H, Kong YY, Yoshida R, Elia AJ, Hakem A, Hakem R, Penninger JM and Mak TW (1998) Apaf1 is required for mitochondrial pathways of apoptosis and brain development. Cell 94: 739-750

9. Cecconi F, Alvarez-Bolado G, Meyer BI, Roth KA and Gruss P (1998) Apaf1 (CED-4 homolog) regulates programmed cell death in mammalian development. Cell 94: 727-737

10. Gao Y, Sun Y, Frank KM, Dikkes P, Fujiwara Y, Seidl KJ, Sekiguchi JM, Rathbun GA, Swat W, Wang J, Bronson RT, Malynn BA, Bryans M, Zhu C, Chaudhuri J, Davidson L, Ferrini R, Stamato T, Orkin SH, Greenberg ME and Alt FW (1998) A critical role for DNA end-joining proteins in both lymphogenesis and neurogenesis. Cell 95: 891-902 
11. GuY, Sekiguchi J, Gao Y, Dikkes P, FrankK, Ferguson D, Hasty $P$, Chun J and Alt FW (2000) Defective embryonic neurogenesis in Ku-deficient but not DNAdependent protein kinase catalytic subunit-deficient mice. Proc. Natl. Acad. Sci. USA 97: 2668-2673

12. Critchlow SE and Jackson SP (1998) DNA end-joining: from yeast to man. Trends Biochem. Sci. 23: $394-398$

13. Smith GC and Jackson SP (1999) The DNA-dependent protein kinase. Genes Dev. 13: $916-934$

14. Grawunder U, Zimmer D, Kulesza P and Lieber MR (1998) Requirement for an interaction of XRCC4 with DNA ligase IV for wild-type V(D)J recombination and DNA double-strand break repair in vivo. J. Biol. Chem. 273: 24708-24714

15. Dantzer F, Schreiber V, Niedergang C, Trucco C, FlatterE, De La Rubia G, Oliver J, Rolli V, Menissier-De Murcia J and De Murcia G (1999) Involvement of poly(ADP-ribose) polymerase in base excision repair. Biochimie 81: 69-75

16. Smith GC, Di Fagagna F, Lakin ND and Jackson SP (1999) Cleavage and inactivation of ATM during apoptosis. Mol. Cell. Biol. 19: 6076-6084

17. Meyn MS (1999) Ataxia-telangiectasia, cancer and the pathobiology of the ATM gene. Clin. Genet. 55: 289-304

18. Frank KM, Sekiguchi JM, Seidl KJ, Swat W, Rathbun GA, Cheng HL, Davidson L, Kangaloo L and Alt FW (1998) Late embryonic lethality and impaired V(D)J recombination in mice lacking DNA ligase IV. Nature 396: 173-177

19. Barnes DE, Stamp G, Rosewell I, Denzel A and Lindahl T (1998) Targeted disruption of the gene encoding DNA ligase IV leads to lethality in embryonic mice. Curr. Biol. 8: 1395-1398

20. Ouyang H, Nussenzweig A, Kurimasa A, Soares VC, LiX, Cordon-Cardo C, LiW, Cheong N, Nussenzweig M, lliakis G, Chen DJ and Li GC (1997) Ku70 is required for DNA repair but not for $T$ cell antigen receptor gene recombination in vivo. J. Exp. Med. 186: $921-929$

21. Taccioli GE, Amatucci AG, Beamish HJ, Gell D, Xiang XH, Torres Arzayus MI, Priestley A, Jackson SP, Marshak Rothstein A, Jeggo PA and Herrera VL (1998) Targeted disruption of the catalytic subunit of the DNA-PK gene in mice confers severe combined immunodeficiency and radiosensitivity. Immunity 9:355-366

22. Gao Y, Chaudhuri J, Zhu C, Davidson L, WeaverDT and AltFW (1998)A targeted DNA-PKcs-null mutation reveals DNA-PK independent functions for KU in V(D)J recombination. Immunity 9: 367-376

23. Jhappan C, Morse HC 3rd, Fleischmann RD, Gottesman MM and Merlino G (1997) DNA-PKcs: a T-cell tumour suppressor encoded at the mouse scid locus. Nat. Genet. 17: 483-486

24. Bosma MJ and Carroll AM (1991) The SCID mouse mutant: definition, characterization, and potential uses. Annu. Rev. Immunol. 9: 323-350

25. Chakravarthy BR, Walker T, Rasquinha I, Hill IE and Macmanus JP (1999) Activation of DNA-dependent protein kinase may play a role in apoptosis of human neuroblastoma cells. J. Neurochem. 72: 933-942

26. Masutani M, Nozaki T, Nishiyama E, Shimokawa T, Tachi Y, Suzuki H, Nakagama H, Wakabayashi K and Sugimura T (1999) Function of poly(ADPribose) polymerase in response to DNA damage: gene-disruption study in mice. Mol. Cell. Biochem. 193: 149-152

27. Shieh SM, Ame JC, Wilson MV, Wang ZQ, Koh DW, Jacobson MK and Jacobson EL (1998) Poly(ADP-ribose) polymerase null mouse cells synthesize ADPribose polymers. J. Biol. Chem. 273: 30069-30072

28. Clarke PGH (1999) Apoptosis versus necrosis: how valid a dichotomy for neurons? In Cell death and Diseases of the Nervous System. Koliatsos V and Ratan R eds. Totowa, New Jersey, Humana Press, pp. 3-28

29. Wyllie AH, Kerr JF and Currie AR(1980) Cell death: the significance of apoptosis. Int. Rev. Cytol. 68: 251-306

30. Upender MB, Dunn JA, Wilson SM and Naegele JR (1997) Immunoglobulin molecules are present in early-generated neuronal populations in the ratcerebral cortex and retina. J. Comp. Neurol. 384: 271-282

31. Weiner JA and Chun J (1997) Maternally derived immunoglobulin light chain is present in the fetal mammalian CNS. J. Neurosci. 17: 3147-3156

32. Danska JS, Holland DP, Mariathasan S, Williams KM and Guidos CJ (1996) Biochemical and genetic defects in the DNA-dependent protein kinase in murine scid lymphocytes. Mol. Cell. Biol. 16: $5507-5517$

33. Achari Y and Lees-Miller SP (2000) Detection of DNA dependent Protein kinase in extracts from human and rodent cells. Methods in MolecularBiology 99:85-97

34. Gell D and Jackson SP (1999) Mapping of protein-protein interactions within the DNA-dependent protein kinase complex. Nucleic Acids Res. 27: 3494-3502
35. Buck $L$ and Axel R (1991) A novel multigene family may encode odorant receptors: a molecular basis for odor recognition. Cell 65: 175-187

36. Beamish HJ, Jessberger R, Riballo E, Priestley A, Blunt T, Kysela B and Jeggo PA (2000) The C-terminal conserved domain of DNA-PKcs, missing in the SCID mouse, is required for kinase activity. Nucleic Acids Res. 28: 1506-1513

37. Casciola-Rosen LA, Anhalt GJ and Rosen A (1995) DNA-dependent protein kinase is one of a subset of autoantigens specifically cleaved early during apoptosis. J. Exp. Med. 182: 1625-1634

38. Song Q, Lees-Miller SP, Kumar S, Zhang Z, Chan DW, Smith GC, Jackson SP, Alnemri ES, Litwack G, Khanna KKand Lavin MF (1996) DNA-dependent protein kinase catalytic subunit: a target for an ICE-like protease in apoptosis. EMBO. J. 15: $3238-3246$

39. Mcconnell KR, Dynan WS and Hardin JA (1997) The DNA-dependent protein kinase catalytic subunit (p460) is cleaved during Fas-mediated apoptosis in Jurkat cells. J. Immunol., 158: 2083-2089

40. Anderson CW and Lees-Miller SP (1992) The nuclear serine/threonine protein kinase DNA-PK. Crit. Rev. Eukaryot. Gene Expr. 2: 283-314

41. Blunt T, Gell D, Fox M, Taccioli GE, Lehmann AR, Jackson SP and Jeggo PA (1996) Identification of a nonsense mutation in the carboxyl-terminal region of DNA-dependent protein kinase catalytic subunit in the scid mouse. Proc. Natl. Acad. Sci. USA 93: 10285-10290

42. Gottlieb TM and Jackson SP (1993) The DNA-dependent protein kinase requirement for DNA ends and association with Ku antigen. Cell 72: 131-142

43. Ruscetti T, Lehnert BE, Halbrook J, Le Trong H, Hoekstra MF, Chen DJ and Peterson SR (1998) Stimulation of the DNA-dependent protein kinase by poly(ADP-ribose) polymerase. J. Biol. Chem. 273: 14461 - 14467

44. Rotman G and Shiloh Y (1997) Ataxia-telangiectasia: is ATM a sensor of oxidative damage and stress? Bioessays 19: 911-917

45. Rotman G and Shiloh Y (1998) ATM: from gene to function. Hum. Mol. Genet. 7: $1555-1563$

46. Lavin MF and Shiloh Y (1997) The genetic defect in ataxia-telangiectasia. Annu. Rev. Immunol. 15: 177-202

47. Eilam R, Peter Y, Elson A, Rotman G, Shiloh Y, Groner Y and Segal M (1998) Selective loss of dopaminergic nigro-striatal neurons in brains of Atm-deficient mice. Proc. Natl. Acad. Sci. USA 95: 12653-12656

48. Savitsky K, Bar-Shira A, Gilad S, Rotman G, Ziv Y, Vanagaite L, Tagle DA, Smith S, Uziel T, Sfez S and et al. (1995) A single ataxia telangiectasia gene with a product similar to $\mathrm{PI}-3$ kinase [see comments]. Science 268: 1749-1753

49. Rosen A and Casciola-Rosen L (1997) Macromolecular substrates for the ICElike proteases during apoptosis. J. Cell. Biochem. 64: 50-54

50. Duriez PJ and Shah GM (1997) Cleavage of poly(ADP-ribose) polymerase: a sensitive parameter to study cell death. Biochem. Cell. Biol. 75: 337-349

51. Satoh MS and Lindahl T (1992) Role of poly(ADP-ribose) formation in DNA repair. Nature 356: $356-358$

52. Laplaca MC, Raghupathi R, Verma A, Pieper AA, Saatman KE, Snyder SH and Mcintosh TK (1999) Temporal patterns of poly(ADP-ribose) polymerase activation in the cortex following experimental brain injury in the rat. J. Neurochem. 73: 205-213

53. Blaschke AJ, Staley K and Chun J (1996) Widespread programmed cell death in proliferative and postmitotic regions of the fetal cerebral cortex. Development 122: $1165-1174$

54. Chun J (2000) Cell death, DNA breaks and possible rearrangements: an alternative view. Trends Neurosci. 23: 407-408

55. Velier JJ, Ellison JA, Kikly KK, Spera PA, Barone FC and Feuerstein GZ (1999) Caspase- 8 and caspase- 3 are expressed by different populations of cortical neurons undergoing delayed cell death after focal stroke in the rat. J. Neurosci. 19: $5932-5941$

56. Yue T-L, Wang C, Romanic AM, Kikly K, Keller P, Dewolf WE, Hart TK, Thomas HC, Storer B, Gu J-L, Wang X and Feuerstein GZ (1998) Staurosporine-induced apoptosis in cardiomyocytes: a potential role of caspase-3. J. Mol. Cell. Cardiol. 30: $495-507$

57. Han Z, Malik N, Carter T, Reeves WH, Wyche JH and Hendrickson EA (1996) DNA-dependent protein kinase is a target for a CPP32-like apoptotic protease. J. Biol. Chem. 271: 25035-25040 